\title{
MODEL DEVELOPMENT OF RIDE SPLITTING SERVICE WITH RESOURCE SHARING SCHEME ON RIDE SOURCING (ONLINE TAXI) SERVICES IN JAKARTA
}

\author{
Helen Burhan ${ }^{1 *}$, Sutanto Soehodho ${ }^{2}$, Nahry ${ }^{1}$ \\ ${ }^{I}$ Department of Mathematics, Universitas Indonesia, Depok, Indonesia \\ ${ }^{2}$ Department of Civil Engineering, Universitas Indonesia, Depok, Indonesia \\ *Corresponding author: helen.burhan@sci.ui.ac.id
}

(Received: 21 $1^{\text {st }}$ June 2020; Accepted: $24^{\text {th }}$ October 2020; Published on-line: $4^{\text {th }}$ January 2021)

\begin{abstract}
This study aims to solve the increasing number of vehicles for ride-sourcing or online taxi service on the road and the operational issues in those services by developing an optimization model of ride-splitting services in the online taxi with a resource sharing (sharing platform) scheme. Ride-splitting service is a ride-sourcing service where one vehicle can serve two or more request customers at a similar time. Meanwhile, the resource-sharing scheme interlinks drivers from different platforms in providing services to the customers. That is, a driver from platform $\mathrm{X}$ can serve customers from platform $\mathrm{Y}$ and vice versa, with a predetermined profit sharing. We formulate the optimization problem as a new modified weighted bipartite matching and solve the problem using a greedy heuristic method. Based on the simulation, the proposed model can generate higher overall profit for all vehicles serving passengers, use fewer vehicles, and lower passengers'waiting time.
\end{abstract}

\begin{abstract}
ABSTRAK: Kajian ini bertujuan menyelesaikan jumlah penambahan kenderaan angkutanberpusat atau servis teksi dalam talian di atas jalan raya dan isu operasi dalam perkhidmatan dengan membangunkan model pengoptimuman pada servis angkutan-pecahan bagi teksi dalam talian dengan skim perkongsian sumber (platform bersama). Servis angkutan-pecahan adalah servis angkutan-berpusat di mana satu kenderaan menyediakan perkhidmatan kepada dua atau lebih permintaan pengguna pada satu-satu masa. Manakala, perkongsian sumber menghubungkan pemandu dengan platform berlainan dalam menyediakan servis untuk penumpang. Iaitu, pemandu platform $\mathrm{X}$ boleh mengangkut penumpang platform $\mathrm{Y}$ dan sebaliknya, dengan menentukan terlebih dahulu keuntungan bersama. Kajian ini diformulasi dengan pengoptimuman masalah sebagai perubahan terbaru dalam menilai kesesuian keduadua pihak dan menyelesaikan masalah menggunakan kaedah heuristik rakus. Berdasarkan simulasi ini, model yang dicadangkan dapat menghasilkan keuntungan keseluruhan lebih tinggi bagi semua kenderaan perkhidmatan, dengan mengurangkan jumlah kenderaan dan masa menunggu penumpang.
\end{abstract}

KEYWORDS: Ride Sourcing (Online Taxi) Services, Ride Splitting Service, Resource Sharing Scheme, Modified Weighted Bipartite Matching, Greedy Heuristic Method.

\section{INTRODUCTION}

In line with the increasing usage of ride-sourcing service, which is more commonly known as online taxi, new problems stemming from the increasing usage of the service are also arising. One of those problems is the increased number of private vehicles on the road. This is due to the attractive idea of online taxi as a new business potential, so that idle private vehicles are now utilized as the online taxi fleet, some business owners even buy new cars purposely to be 
rented for online taxi services [1]. The increased usage of private vehicles for the online taxi services is not in accordance with the initial purpose of ride-sourcing service, which was initially a ride-sharing concept that was designed to minimize the usage of private vehicles in order to reduce traffic $[2,3]$. On the other hand, one of the many services offered by the online taxi provider is ride-splitting, a service that is unfortunately still underused. Ride-splitting service is a ride-sourcing service that is in line with the actual concept of ride sharing, where one vehicle (single driver) can serve two or more riders (multi-riders) at a similar time [4].

Currently, there are two big companies providing online taxi services in Jakarta whose operational services are not yet optimized. This can be concluded from the long waiting time for customers to be picked up, which is sometimes a lot longer that the estimate time shown on the app; and also from the surge pricing system, where the fare will be higher than the standard fare when the demand for services is high and the vehicle availability is low, the surge pricing system is deemed as non-transparent so that it can disadvantage consumers [5]. In the previous research, Burhan et.al [6] developed an optimized model of pure ride-sourcing service (single driver - single rider) with a resource sharing scheme to tackle the operational problems. Therefore, this study aims to solve the increasing number of vehicles for online taxi on the road and the operational issues in online taxi services, by developing an optimization model of ridesplitting services in online taxi with a resource sharing (sharing platform) scheme.

To optimize the ride-splitting service with resource sharing scheme, an optimized route is sought to pick up and drop off two or more customer requests (in this research is limited to only two requests) from the nearby or adjacent area at the similar travel time. The resource sharing scheme here is the same one as defined by Burhan et.al [6], which is interlinking drivers from different operators (platforms) in providing services to the customers, where a driver from platform $\mathrm{X}$ can serve customers from platform $\mathrm{Y}$ and vice versa, with a predetermined profit sharing. The mathematical model in optimizing issues in this study will be using a new modified weighted bipartite matching problem, while the solving method will be using greedy heuristic method.

The rest of the paper is organized as follows. Section 2 presents a literature review, while section 3 describes the problem formulation, and section 4 describes the solution method, section 5 present the computational experiment, and finally, section 6 concludes and illustrates future research directions.

\section{LITERATURE REVIEW}

Ride-sourcing service, which is more commonly known as online taxi, is a public transportation service using private owned vehicles as fleet to serve customers as taxi service using technology of smartphones, GPS and GIS [2,3]. Based on the type of service offered, the service can be grouped into two types [4], pure ride-sourcing (single driver, single rider) and ride splitting (single driver, multi riders). In pure ride sourcing, a driver of personal vehicle is connected to one request customer, and in the ride-splitting service, a driver is connected to two or more request customers in which customers can choose to split (share) a ride and fare. Based on that classification, ride- splitting is the appropriate form of ride-sourcing based on the ride-sharing concept for single driver - multi rider, so that the problem of optimizing the ride-splitting service is the optimization problem in finding the vehicle route to pick up and drop off passengers [7].

The optimization problem in finding the vehicle route to pick up and and drop off passengers on ride-splitting service is similar to dynamic pick up and delivery problem with time windows [8]. Generally, the pick up and delivery problems with time windows is one 
variant of vehicle routing problem which aims to find the optimal vehicle route to deliver and pick up a number of customers in an interval of time (time windows), taking into account a number of constraints such as vehicle capacity and some other precedent constraints, with minimum costs [9]. The dynamic term here refers to the requests which gradually revealed throughout the day, so that vehicle routes are constructed in real-time [10].

Several previous studies that discussed the problem of optimizing ride-sharing services for the case of a single driver-multi rider, some of which are, Hosni et al. [11] use mixed integer programming to model the problem of maximize profit for shared taxi problem and present a Lagrangian decomposition approach as well as two heuristics to solve the problem, Wang et.al [12] use binary integer programming to model the problem of minimize cost and travel time for a pickup and delivery problem with the use of HOV lanes and use Tabu search heuristic to solve the problem, Santos and Xavier [13] use mixed integer programming to model the problem of maximize the number of served requests and minimize the cost for the ride-sharing problem and solved the problem by a greedy randomized adaptive search procedure, Mahmoudi and Zhou [14] propose a new time discretized multi-commodity network flow model for ride-sharing problem within state space-time network to minimize cost and using a forward dynamic programming solution algorithm and Lagrangian approach to solve the problem. While Bei and Zhang [15] use a three-dimensional matching problem to minimize cost for the ride-sharing problem and use a two-phase greedy approach to solve the problem. To the best of our knowledge, the previous studies have never been including maximizing profit and minimizing waiting time in the objective function simultaneously and explicitly. Therefore, in this study, we will use a new modified weighted bipartite graph problem to formulate the optimization problem of ride splitting service to maximize the driver's profit while minimizing passenger's waiting time.

In the meantime, researches relating to the operational problems in ride-sourcing services are discussing more of the surge pricing problems; because surge pricing is considered as lack transparency and is harmful to the consumer [16-18]. However, since the price for ride service cannot be unlimited, there is usually a reasonable or legitimate range of prices in practice. Such a constrained surge pricing strategy fails to balance demand and supply in certain cases, e.g., even adopting the maximum allowed price cannot reduce the demand to an affordable level during peak hours [19]. Therefore, this study is developing a resource sharing scheme based on research conducted by Burhan, $\mathrm{H}$, et.al [6] to solve the surge pricing problems in ridesourcing services.

\section{PROBLEM FORMULATION}

In ride-splitting service with resource sharing scheme, customer from platform $X$ can be served by vehicle from platform Y, and the other way around, with a profit sharing between platforms that is predetermined beforehand. With the predetermined scheme, characteristics of the ride-splitting service with the resource sharing scheme in this paper, are as follows:

- Customer will get less waiting time

- Driver will get more profit due to less operational cost by picking up customer from the different platform, whose pick-up location is closer to the driver's position, rather than picking up customer from the same platform but whose pick-up location is quite far from the driver's position.

- Matching rate between driver and passenger/customer is also increasing, because the probability is bigger for the customer whose pick-up time and location is similar to the driver, as opposed to when compared to the possibility from only the same platform. 
Assume, there are two different operators (platforms) providing ride-splitting services, where it can be enlarged to $n$ platforms and a homogenous fleet of vehicles with the same capacities. The request from a customer in this study arrives dynamically, thus the customer's requests and available vehicles will be grouped first, based on a period of time, and then the optimization process to assign vehicle and passengers is done statically per period. The period length is based on an acceptable time limit of a customer to wait for a decision to be picked up and time for the optimization process. The first period starts at the time, at which the first request from a customer arrived.

In the optimization process, initially, we must pair potential vehicles which feasible to serve a request customer by generating the first weighted bipartite graph. Then, we will get a set of feasible vehicle and the first customer pairs. In this study, the ride splitting service is limited to serving only two request customers in one trip. Thus, next stage is to generate a second weighted bipartite graph to pair a vehicle and the first customer with a potential second request customer. The objective of the optimization problem is to maximize the total profit earned by drivers (vehicles) while minimizing the total passenger's waiting time. Then, we model the problem using a new modified weighted bipartite matching. The final stage, use a greedy heuristic method to solve the problem.

Next, we present the process of generating first weighted bipartite graph as the first stage for the optimization process.

\subsection{First Weighted Bipartite Graph}

Let $k$ and $r$ be the number indexes for platform which requested by customer, where $\boldsymbol{k}, \boldsymbol{r}=$ $\mathbf{1}, \mathbf{2}$ and $\boldsymbol{\tau}$ be the period for optimization process. Let $\boldsymbol{P}_{\boldsymbol{k} \boldsymbol{l}}^{\boldsymbol{\tau}}$ be the $\boldsymbol{l}-\boldsymbol{t} \boldsymbol{h}$ passenger of platform $\boldsymbol{k}$ in period $\boldsymbol{\tau}$ and $\boldsymbol{V}_{\boldsymbol{r} \boldsymbol{s}}^{\boldsymbol{\tau}}$ be the s-th available vehicle of platform $\boldsymbol{r}$ in period $\boldsymbol{\tau}$. Then:

- $P_{k}^{\tau}$ be a set of customers who request vehicle from platform $k$ in period $\tau$, where: $\quad P_{k}^{\tau}=\left\{P_{k l}^{\tau} \mid\right.$ the $l-t h$ passenger of platform $k$ in period $\left.\tau ; l=1,2, \ldots, n_{k}\right\}$, for $k=1,2$ and $P^{\tau}$ be the set of customers who request vehicle in period $\tau$.

- $V_{r}^{\tau}$ be a set of available vehicles from platform $r$ in period $\tau$, where:

$V_{r}^{\tau}=\left\{V_{r s}^{\tau} \mid\right.$ the $s-$ th vehicle of platform $r$ in period $\left.\tau ; s=1,2, \ldots, m_{r}\right\}$, for $r=1,2$ and $V^{\tau}$ be the set of available vehicles in period $\tau$.

Note that $P^{\tau_{i}}$ consists of all new customer requests in period $\tau_{i}$ and all assigned passengers in the previous period $\tau_{i-1}$, but still not get a passenger pair to share a ride, for $i=2,3, \ldots$. Likewise, $V^{\tau_{i}}$ consists of all newly available vehicles in period $\tau_{i}$ and all available vehicles which still eligible to serve a customer from the previous period $\tau_{i-1}$, for $i=2,3, \ldots$.

Each passenger $P_{k l}^{\tau}$ is associated with time at which customer request a vehicle $t_{\text {request_ }} P_{k l}^{\tau}$, origin or pick up location $o_{P_{k l}^{\tau}}$, destination or drop off location $d_{P_{k l}^{\tau}}$, an earliest departure time $e_{\text {dept }_{P_{k l}^{\tau}}^{\tau}}$, a latest departure time $l_{\operatorname{dept}_{P_{k l}^{\tau}}}$, and the number of passenger $q_{P_{k l}^{\tau}}$. Also, passenger $P_{k l}^{\tau}$ must arrive at destination at least on $e_{a r r_{-} P_{k l}^{\tau}}$, and not after $l_{a r r_{-} P_{k l}^{\tau}}$, and cannot ride a vehicle more than $t_{\text {maxride }} P_{k l}^{\tau}$. While, each available vehicle $V_{r s}^{\tau}$ is associated with origin or current location $i_{V_{r s}^{\tau}}^{\tau}$, time to leave from or arrive at location on $\operatorname{tim} e_{i_{V_{r s}^{\tau}}^{\tau}}^{V_{r}^{\tau}}$, maximum capacity $Q_{V_{r s}^{\tau}}$, and vehicle's occupation $V_{r s_{-}}^{\tau}$ occ.

Let $G_{1}^{\tau}=\left(N_{1}^{\tau}, E_{1}^{\tau}\right)$ be the first weighted bipartite graph for optimization process, where $N_{1}^{\tau}$ be the set of nodes of $G_{1}^{\tau}$ and $E_{1}^{\tau}$ be the set of edges of $G_{1}^{\tau}$.

Defined $N_{1}^{\tau}=V^{\tau} \cup P^{\tau}$ be a bipartite node set of all request customers and available vehicles in period $\tau$. For each passenger $P_{k l}^{\tau}$ in $P^{\tau}$, the distance $D_{i_{V_{r s}^{\tau}}^{\tau} o_{P_{k l}^{\tau}}^{\tau}}$ and the travel time $T T_{i_{V_{r s}^{\tau}} o_{P_{k l}^{\tau}}^{\tau}}$ be 
a distance and a travel time of shortest path from origin $o_{P_{k l}^{\tau}}$ to destination $d_{P_{k l}^{\tau}}$. For each vehicle $V_{r s}^{\tau}$ in $V^{\tau}$, the distance $D_{i_{V_{r s}^{\tau}}^{\tau} O_{P_{k l}^{\tau}}^{\tau}}$ and the travel time $T T_{i_{V_{r s}^{\tau}}^{\tau} O_{P_{k l}^{\tau}}^{\tau}}$ be a distance and a travel time of shortest path from vehicle's origin (current) location $i_{V_{r s}^{\tau}}$ to passenger's origin $o_{P_{k l}^{\tau}}^{\tau}$.

For each passenger $P_{k l}^{\tau}$, earliest and latest departure time, earliest and latest arrival time, and maximum ride time are determined with the following formula:

$$
\begin{aligned}
& e_{\text {dept }_{P_{k l}^{\tau}}^{\tau}}:=t_{\text {request_P } P_{k l}^{\tau}}+\lambda_{\text {early }} \\
& l_{\operatorname{dept}_{P_{k l}^{\tau}}^{\tau}}:=e_{\operatorname{dept}_{P_{k l}^{\tau}}}+\lambda_{\text {late }}
\end{aligned}
$$

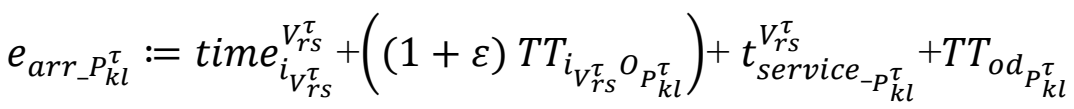

$$
\begin{aligned}
& l_{a r r_{-} P_{k l}^{\tau}}:=e_{a r P_{P l}^{\tau}}+\lambda_{\text {late }} \\
& t_{\text {maxride_P }}^{\tau}:=\left((1+\mu) T T_{o d_{P_{k l}^{\tau}}^{\tau}}\right)
\end{aligned}
$$

where $\lambda_{\text {early }}$ be a level of service for early departure time; $\lambda_{\text {late }}$ be a level of service for early departure or arrival time; $t_{\text {service }}^{V_{-P_{k l}^{\tau}}^{\tau}}$ be time for passenger to get into (get off from) a vehicle; $(1+\varepsilon)$ and $(1+\mu)$ be multiplier factor for tolerance time deviation, with $0<\varepsilon, \mu<1$.

Vehicle $V_{r s}^{\tau}$ is feasible to serve a passenger $P_{k l}^{\tau}$, if the following criteria are met.

1) Time Constraints:

a) Vehicle must arrive at passenger's origin on departure time windows:

$$
e_{\text {dept }_{P_{k l}^{\tau}}^{\tau}} \leq \operatorname{time}_{i_{V_{r s}^{\tau}}^{V_{r s}^{\tau}}}^{V^{\tau}}+\left((1+\varepsilon) T T_{i_{V_{r s}^{\tau}}^{\tau} O_{P_{k l}^{\tau}}^{\tau}}\right) \leq l_{\operatorname{dept}_{P_{k l}^{\tau}}^{\tau}}
$$

b) Vehicle must arrive at passenger's destination on arrival time windows:

$$
e_{a r r_{-} P_{k l}^{\tau}}^{\tau} \leq t i m e_{i_{V_{r s}^{\tau}}^{\tau}}^{V_{r s}^{\tau}}+\left((1+\varepsilon) T T_{i_{V_{r s}^{\tau}}^{\tau} O_{P_{k l}^{\tau}}^{\tau}}\right)+t_{\text {service }_{-P_{k l}^{\tau}}^{V_{r s}^{\tau}}}^{{ }^{\tau}}+T T_{o d_{P_{k l}^{\tau}}^{\tau}} \leq l_{\text {arr } P_{k l}^{\tau}}
$$

2) Capacity Constraint:

The number of passengers in each request must be less than or equal to available vehicle's capacity:

$$
q_{P_{k l}^{\tau}} \leq Q_{V_{r s}^{\tau}}
$$

Let $P_{k l}^{\tau}$ in $P^{\tau}$ and $V_{r s}^{\tau}$ in $V^{\tau}$. Defined an edge in $E_{1}^{\tau}$ be a pair of $\left(V_{r s}^{\tau}, P_{k l}^{\tau}\right)$, where vehicle $V_{r s}^{\tau}$ is met the feasible criterion in (6) $-(8)$ to serve passenger $P_{k l}^{\tau}$. Then, $E_{1}^{\tau}=$ $\left\{\left(V_{r s}^{\tau}, P_{k l}^{\tau}\right) \mid P_{k l}^{\tau}\right.$ and $V_{r s}^{\tau}$ are feasible match; $\left.V_{r s}^{\tau} \in V^{\tau}, P_{k l}^{\tau} \in P^{\tau}\right\}$. The weight of each edge $\left(V_{r s}^{\tau}, P_{k l}^{\tau}\right)$ in $E_{1}^{\tau}$ is defined as the fare that has to be paid by passenger $P_{k l}^{\tau}$ served by vehicle $V_{r s}^{\tau}$, where the fare is calculated by using the following formula:

$$
F^{P_{k l}^{\tau}}=\text { Tariff }_{k} \times D_{o d_{-} P_{k l}^{\tau}}
$$

where Tarif $_{k}$ is tariff of platform $k$ for ride splitting service per 1 distance unit.

Next, mathematical model for the optimization problem of ride splitting service with resource sharing scheme will be presented. Before that, we generate a second weighted bipartite graph.

\subsection{New Modified Weighted Bipartite Matching Problem}


Let $G_{2}^{\tau}=\left(N_{2}^{\tau}, E_{2}^{\tau}\right)$ be the second weighted bipartite graph for optimization process, where $N_{2}^{\tau}$ be the set of nodes of $G_{2}^{\tau}$ and $E_{2}^{\tau}$ be the set of edges of $G_{2}^{\tau}$.

Let $N_{2}^{\tau}=V^{\tau} P^{\tau} \cup D V^{\tau} P^{\tau}$, be a bipartite set of nodes of graph $G_{2}^{\tau}$. For $V_{r s}^{\tau} \in V^{\tau}$ and $P_{k l}^{\tau} \in P^{\tau}$, defined $V_{r s}^{\tau} P_{k l}^{\tau}$ be a node in $V^{\tau} P^{\tau}$ if only if $\left(V_{r s}^{\tau}, P_{k l}^{\tau}\right)$ is an edge in $E_{1}^{\tau}$. Thus, $V^{\tau} P^{\tau}=$ $\left\{V_{r s}^{\tau} P_{k l}^{\tau} \mid\left(V_{r s}^{\tau}, P_{k l}^{\tau}\right)\right.$ is an edge in $\left.E_{1}^{\tau} ; V_{r s}^{\tau} \in V^{\tau}, P_{k l}^{\tau} \in P^{\tau}\right\}$ and $D V^{\tau} P^{\tau}$ is a duplication set of $V^{\tau} P^{\tau}$ where $D V^{\tau} P^{\tau}=\left\{V_{r, s}^{\tau} P_{k \prime l}^{\tau} \tau^{\tau} \mid\right.$ if $\left.V_{r s}^{\tau} P_{k l}^{\tau} \in V^{\tau} P^{\tau}\right\}$.

Let $V_{r S}^{\tau} P_{k l}^{\tau}$ be a node in $V^{\tau} P^{\tau}$ and $V_{r^{\prime} s^{\prime}}^{\tau} P_{k^{\prime \prime l}}^{\tau}$, be a node in $D V^{\tau} P^{\tau}$, defined, an edge in $E_{2}^{\tau}$ be a pair of $\left(V_{r s}^{\tau} P_{k l}^{\tau}, V_{r^{\prime} s}^{\tau} P_{k \prime l}^{\tau}\right)$, where $r=r^{\prime}, s=s^{\prime}$ and $V_{r s}^{\tau}$ is feasible to serve customers $P_{k l}^{\tau}$ and $P_{k^{\prime} l^{\prime},}^{\tau}$. Note that, in the edge $\left(V_{r s}^{\tau} P_{k l}^{\tau}, V_{r^{\prime} s^{\prime}}^{\tau} P_{k^{\prime} l^{\prime}}^{\tau}\right), V_{r s}^{\tau}$ and $V_{r^{\prime} s^{\prime}}^{\tau}$ have to be the same vehicles. Thus, $E_{2}^{\tau}=\left\{\left(V_{r s}^{\tau} P_{k l}^{\tau}, V_{r \prime s}^{\tau} P_{k^{\prime} l l}^{\tau}\right) \mid r=r^{\prime}, s=s^{\prime}\right.$ and $V_{r s}^{\tau}$ is feasible match with $P_{k l}^{\tau}$ and $P_{k^{\prime} l, l}^{\tau}$; $\left.V_{r s}^{\tau} P_{k l}^{\tau} \in V^{\tau} P^{\tau}, V_{r^{\prime}, s^{\prime}}^{\tau} P_{k \prime l}^{\tau}, \in D V^{\tau} P^{\tau}\right\}$.

Route of vehicle $V_{r s}^{\tau}$ to pick up and drop off customers $P_{k l}^{\tau}$ and $P_{k^{\prime} l}^{\tau}$, Route $_{V_{r s-}^{\tau} P_{k l-}^{\tau} P_{k^{\prime} l l}^{\tau}{ }^{\prime}}$ is defined as the shortest path from vehicle's current location $i_{V_{r s}^{\tau}}^{\tau}$ to the first passenger's origin $o_{P_{k l}^{\tau}}^{\tau}$, then to the second passenger's origin $o_{P_{k^{\prime} l^{\prime}}^{\tau}}$ and next to passenger's destination $d_{P_{k l}^{\tau}}$ or $d_{P_{k^{\prime} \prime \prime}^{\tau}}^{\tau}$ for which one is the closest. Then, Route $V_{V_{r_{S}}^{\tau} P_{k l}^{\tau} P_{k^{\prime} / l}^{\tau}}^{\tau}$ is the shortest path between route $i_{V_{r s}^{\tau}}^{\tau}-o_{P_{k l}^{\tau}}^{\tau}-o_{P_{k^{\prime} l^{\prime}}^{\tau}}-d_{P_{k l}^{\tau}}-d_{P_{k \prime l l}^{\tau}}$ and route $i_{V_{r s}^{\tau}}-o_{P_{k l}^{\tau}}-o_{P_{k^{\prime} l^{\prime}}^{\tau}}-d_{P_{k^{\prime} l^{\prime}}^{\tau}}-d_{P_{k l}^{\tau}}$. Distance $_{V_{r s}^{\tau} P_{k l-}^{\tau} P_{k \prime l l}^{\tau}}$ and $T T_{V_{r s-}^{\tau} P_{k l-}^{\tau} P_{k^{\prime} l l}^{\tau}}$ are defined as the distance and the travel time of Route $_{V_{r s-}^{\tau} P_{k l-}^{\tau} P_{k \prime l}^{\tau} l^{\tau}}$.

Vehicle $V_{r s}^{\tau}$ is feasible to serve customers $P_{k l}^{\tau}$ and $P_{k \prime l}^{\tau}$, if the following criteria are met:

1) Time feasibility:

a) Vehicle must arrive at passenger's origin on passenger's departure time windows:

- For first passenger, $P_{k l}^{\tau}$ :

$$
e_{\operatorname{dept}_{P_{k l}^{\tau}}^{\tau}} \leq W T_{V_{r s}^{\tau}}^{P_{k l}^{\tau}} \leq l_{\operatorname{dept}_{P_{k l}^{\tau}}^{\tau}}
$$

where $W T_{V_{r s}^{\tau}}^{P_{k l}^{\tau}}$ is passenger $P_{k l}^{\tau}$, s waiting time to be picked up by vehicle $V_{r s}^{\tau}$,

with $W T_{V_{r s}^{\tau}}^{P_{k l}^{\tau}}=t i m e_{i_{V_{r s}^{\tau}}^{\tau}}^{V_{r}^{\tau}}+\left((1+\varepsilon) T T_{i_{r s}^{\tau} o_{P_{k l}^{\tau}}^{\tau}}\right)$

- For second passenger, $P_{k \prime l}^{\tau}$ :

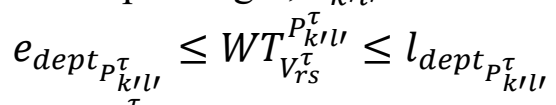

where $W T_{V_{r s}^{\tau}}^{P_{k \prime \prime}^{\tau}}$ is passenger $P_{k^{\prime} l}^{\tau}$ ', 's waiting time to be picked up by vehicle $V_{r s}^{\tau}$,

with $W T_{V_{r s}^{\tau}}^{P_{k^{\prime} l^{\prime}}^{\tau}}=W T_{V_{r s}^{\tau}}^{P_{k l}^{\tau}}+t_{\text {service }}^{V_{r s}^{\tau}}+T T_{O_{P_{k l}}^{\tau} O_{P_{k \prime l}}^{\tau}}$

b) Vehicle must arrive at passenger's destination on passenger's arrival time windows:

If Route $V_{V_{r-} P_{k l-}^{\tau} P_{k \prime l}^{\tau} l^{\tau}}$ is $i_{V_{r s}^{\tau}}^{\tau}-o_{P_{k l}^{\tau}}^{\tau}-o_{P_{k^{\prime} l^{\prime}}^{\tau}}-d_{P_{k l}^{\tau}}-d_{P_{k^{\prime} l}^{\tau} l^{\prime}}$, then:

- For first passenger, $P_{k l}^{\tau}$ :

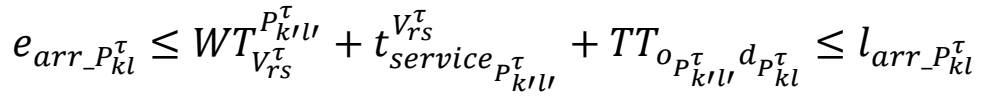

- For second passenger, $P_{k \prime l}^{\tau}$ :

$$
e_{\text {arr }_{-} P_{k^{\prime} l^{\prime}}^{\tau}} \leq t_{\text {service }_{-P_{k l}^{\tau}}^{\tau}}^{V_{r s}^{\tau}}+T T_{I} \leq l_{\text {arr }_{-} P_{k^{\prime} l^{\prime}}^{\tau}}
$$

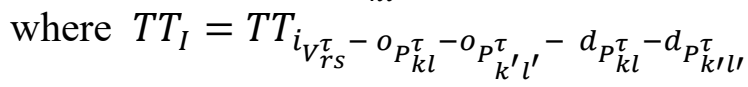

Else if Route $V_{V_{r S} P_{k l-}^{\tau} P_{k^{\prime} l l}^{\tau}}$ is $i_{V_{r s}^{\tau}}^{\tau}-o_{P_{k l}^{\tau}}^{\tau}-o_{P_{k^{\prime} l^{\prime}}^{\tau}}-d_{P_{k^{\prime} l^{\prime}}^{\tau}}-d_{P_{k l}^{\tau}}$, then: 
- For first passenger, $P_{k l}^{\tau}$ :

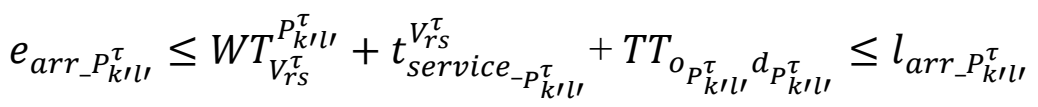

- For second passenger, $P_{k \prime l}^{\tau}$ :

$$
\begin{aligned}
& e_{\text {arr }_{-} P_{k l}^{\tau}}^{\tau} \leq t_{\text {service }_{-P_{k l}^{\tau}}^{\tau}}^{V_{r s}^{\tau}}+T T_{I I} \leq l_{\text {arr } P_{k l}^{\tau}} \\
& \text { where } T T_{I I}=T T_{V_{V_{r s}^{\tau}}^{\tau}-o_{P_{k l}^{\tau}}^{\tau}-o_{P_{k^{\prime} l^{\prime}}^{\tau}}-d_{P_{k^{\prime} l^{\prime}}^{\tau}}-d_{P_{k l}^{\tau}}}
\end{aligned}
$$

c) The time spent by a customer in a vehicle cannot exceed a given value (maximum ride time) :

If Route $_{V_{r S_{-}}^{\tau} P_{k l-}^{\tau} P_{k l^{\prime} l^{\prime}}^{\tau}}=i_{V_{r s}^{\tau}}^{\tau}-o_{P_{k l}^{\tau}}^{\tau}-o_{P_{k^{\prime} l^{\prime}}^{\tau}}-d_{P_{k l}^{\tau}}-d_{P_{k \prime l}^{\tau} \prime^{\tau}}$ then:

- For passenger $\boldsymbol{P}_{\boldsymbol{k l}}^{\boldsymbol{\tau}}$ :

$$
T_{T_{P_{k l}^{\tau}}^{\tau} o_{P_{k \prime l l}^{\tau}}^{\tau}}+t_{\text {service }_{-P_{k / l}^{\tau}}^{\tau}}^{V_{r s}^{\tau}}+T T_{o_{P_{k / l}^{\tau}}^{\tau}} d_{P_{k l}^{\tau}} \leq t_{\text {maxride } P_{k l}^{\tau}}
$$

- $\quad$ For passenger $\boldsymbol{P}_{\boldsymbol{k} / \boldsymbol{l}}^{\boldsymbol{\tau}}$ :

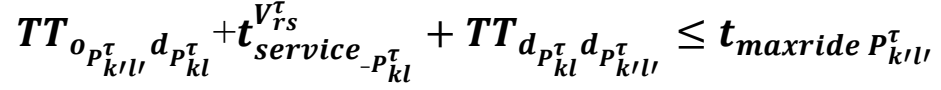

Else if $\boldsymbol{R o u t e}_{V_{r S_{-}}^{\tau} \boldsymbol{P}_{k l-}^{\tau} P_{k^{\prime} l^{\prime}}^{\tau}}$ is $\boldsymbol{i}_{V_{r s}^{\tau}}^{\tau}-\boldsymbol{o}_{P_{k l}^{\tau}}^{\tau}-\boldsymbol{o}_{P_{\boldsymbol{k}^{\prime} l^{\prime}}^{\tau}}-\boldsymbol{d}_{\boldsymbol{P}_{\boldsymbol{k}^{\prime} l^{\prime}}^{\tau}}-\boldsymbol{d}_{\boldsymbol{P}_{k l}^{\tau}}^{\tau}$, then:

- For passenger $\boldsymbol{P}_{\boldsymbol{k} \boldsymbol{l}}^{\boldsymbol{\tau}}$ :

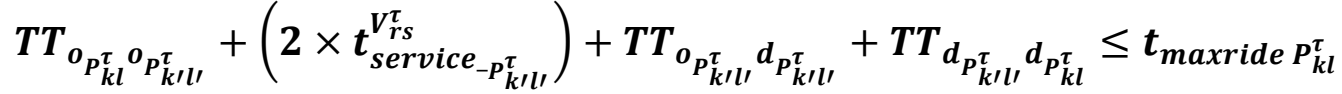

- For passenger $\boldsymbol{P}_{\boldsymbol{k}^{\prime} \boldsymbol{l}^{\prime}}^{\boldsymbol{1}}$ :

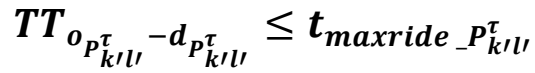

2) Capacity feasibility:

The number of passengers in each request must be less than or equal to available vehicle's capacity:

$$
\boldsymbol{q}_{\boldsymbol{P}_{k l}^{\tau}}^{\tau}+\boldsymbol{q}_{\boldsymbol{P}_{\boldsymbol{k} / l}^{\tau}}^{\tau} \leq \boldsymbol{Q}_{V_{r s}^{\tau}}
$$

Next, we define model of the optimization problem of ride splitting service with resource sharing scheme on graph $\boldsymbol{G}_{2}^{\boldsymbol{\tau}}=\left(\boldsymbol{N}_{2}^{\boldsymbol{\tau}}, \boldsymbol{E}_{2}^{\boldsymbol{\tau}}\right)$, and we use the following decision variables:

$x_{P_{k l}^{\tau}, P_{k \prime l}^{\tau}}^{V_{r s}^{\tau}}=\left\{\begin{array}{c}1, \text { if passengers } P_{k l}^{\tau} \text { and } P_{k, l}^{\tau} \text {, served by vehicle } V_{r s}^{\tau} \\ 0, \text { otherwise }\end{array}\right.$

$z_{V_{r s}^{\tau}}^{P_{k l}^{\tau}}=\left\{\begin{array}{l}1, \text { if vehicle } V_{r s}^{\tau} \text { serves passenger } P_{k l}^{\tau} \\ 0, \text { otherwise }\end{array}\right.$

$w_{V_{r s}^{\tau}}^{P_{k l}^{\tau}}=\left\{\begin{array}{c}1, \text { if platf orm index } k=r \\ \alpha, \text { otherwise }\end{array}\right.$

$\boldsymbol{\alpha}$ is profit sharing multiplier, where $\mathbf{0}<\boldsymbol{\alpha}<\mathbf{1}$

$V_{r s_{-}}^{\tau}$ occ $=\left\{\begin{array}{c}2, \text { if } x_{P_{k l-}^{\tau} P_{k \prime l^{\prime}}^{\tau}}^{V_{r s}^{\tau}}=1 \text { and } P_{k l}^{\tau} \neq P_{k \prime l^{\prime}}^{\tau} \\ 1, \text { if } x_{P_{k l_{-}}^{\tau} P_{k \prime l}^{\tau} P^{\tau}}^{V^{\tau}}=1 \text { and } P_{k l}^{\tau}=P_{k \prime l^{\prime}}^{\tau} \\ 0, \text { else }\end{array}\right.$

$Q_{V_{r s}^{\tau}}=\left\{\begin{array}{c}4, \text { if } V_{r s_{o c c}}^{\tau}=0 \\ 4-q_{P_{k l}^{\tau}} \text {, if } V_{r s_{o c c}}^{\tau}=1 \\ 0, \text { else }\end{array}\right.$ 
For each feasible match $\left(\boldsymbol{V}_{r s}^{\boldsymbol{\tau}} \boldsymbol{P}_{k l}^{\boldsymbol{\tau}}, \boldsymbol{V}_{\boldsymbol{r}^{\prime} \boldsymbol{s}^{\prime}}^{\boldsymbol{\tau}} \boldsymbol{P}_{\boldsymbol{k}^{\prime} \boldsymbol{l}^{\prime}}^{\boldsymbol{\tau}}\right)$ in $\boldsymbol{E}_{2}^{\boldsymbol{\tau}}$, calculate:

1) The operational cost of Route $_{V_{r s-}^{\tau} P_{k l-}^{\tau} P_{k \prime l l}^{\tau}}$ :

$$
o p \cdot \operatorname{cost}_{P_{k l_{-}}^{\tau} P_{k, l^{\prime}}^{\tau}}^{V_{\tau s}^{\tau}}=c_{V_{r s}^{\tau}} \times \text { Distance } V_{r S_{-}}^{\tau} P_{k l-}^{\tau} P_{k, l l}^{\tau}
$$

where $\boldsymbol{c}_{\boldsymbol{V}_{r s}^{\tau}}$ is vehicle $\boldsymbol{V}_{\boldsymbol{r} \boldsymbol{s}}^{\boldsymbol{\tau}}$ 's operational cost per one distance unit

2) The profit of Route $_{V_{r s-}^{\tau} P_{k l}^{\tau} P_{k \prime l}^{\tau}}^{\tau}$ :

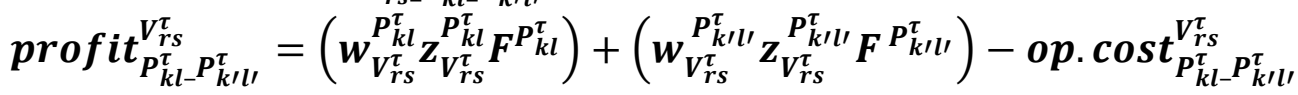

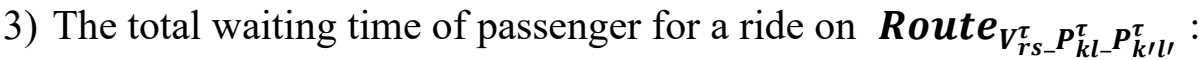

$$
W T_{P_{k l-}^{\tau} P_{k \prime l l}^{\tau}}^{V_{r s}^{\tau}}=W T_{V_{r s}^{\tau}}^{P_{k l}^{\tau}}+W T_{V_{r s}^{\tau}}^{P_{k \prime l}^{\tau}}
$$

4) The money value of total passenger's waiting time:

$$
\overline{W T}_{P_{k l}^{\tau} P_{-k^{\prime} l^{\prime}}^{\tau}}^{V_{\tau s}^{\tau}}=\overline{\overline{w t}}_{\text {money }} \times W T_{P_{k l-}^{\tau} P_{k \prime l l}^{\tau}}^{V_{r s}^{\tau}}
$$

where $\overline{\overline{\boldsymbol{w}}}_{\text {money }}$ is money value of passenger's waiting time per one time unit

5) The weight of edge $\left(\boldsymbol{V}_{r s}^{\tau} \boldsymbol{P}_{k l}^{\tau}, \boldsymbol{V}_{r^{\prime} s^{\prime}}^{\boldsymbol{\tau}} \boldsymbol{P}_{\boldsymbol{k} / l^{\prime}}^{\boldsymbol{\tau}}\right)$ :

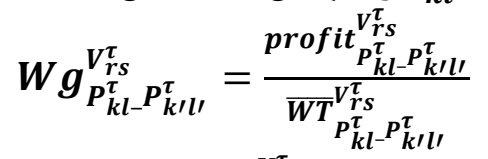

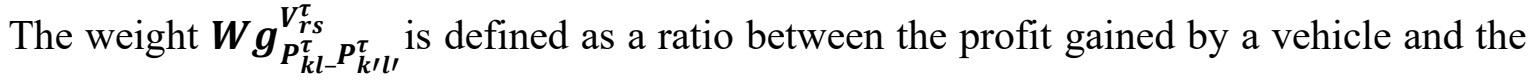
money value of total passenger's waiting time.

The mathematical model for the problem is:

Subject to:

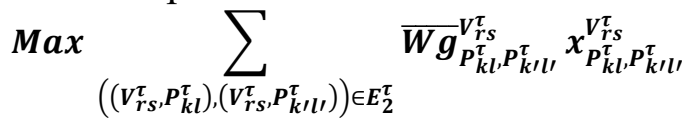

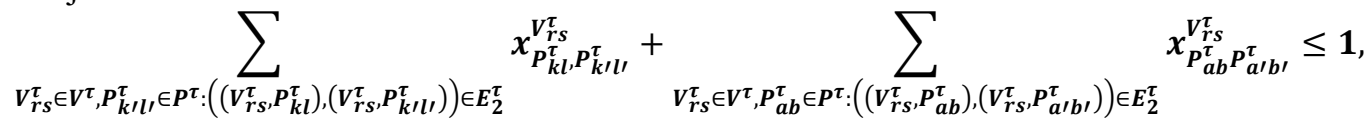

$$
\begin{aligned}
& \forall P_{k l}^{\tau}, P_{k l^{\prime}}^{\tau}, P_{a b}^{\tau}, P_{a^{\prime} b^{\prime}}^{\tau} \in P^{\tau}, \text { for } k=a^{\prime}, l=b^{\prime} \\
& \sum_{P_{k l}^{\tau}, P_{k \prime l l}^{\tau} \in P^{\tau}:\left(\left(V_{r s}^{\tau}, P_{k l}^{\tau}\right),\left(V_{r s}^{\tau}, P_{k \prime l l}^{\tau}\right)\right) \in E_{2}^{\tau}} x_{P_{k l}^{\tau}, P_{k \prime l l}^{\tau}}^{V_{r s}^{\tau}} \leq 1, \quad \forall V_{r s}^{\tau} \in V^{\tau} \\
& x_{P_{k l}^{\tau}, P_{k^{\prime} l^{\prime}}^{\tau}}^{V_{r s}^{\tau}} \in\{\mathbf{0}, \mathbf{1}\}, \quad \forall P_{k l}^{\tau}, P_{k l^{\prime}}^{\tau} \in P^{\tau} ; \forall V_{r s}^{\tau} \in V^{\tau}
\end{aligned}
$$

The objective function (30) maximizes the total weight. Constraints (31) ensures each passenger at most in one feasible match, and (32) ensures each vehicle at most in one feasible match. Finally, constraints (33) enforce the binary condition.

In the next section, we will present the solution algorithm to solve the optimization problem in each period.

\section{SOLUTION METHODOLOGY}

The optimization problem will be solved in three stages. At first, algorithm 1 is performed to obtain a set of feasible pair of a vehicle and the first customer by generating the first weighted 
bipartite graph. Algorithm 2 in the second stage is performed to obtain the set of feasible pair of a vehicle and two request customers by generating second modified weighted bipartite graph. Finally, algorithm 3 is performed to obtain the optimal assignment of vehicle and passenger pair.

Procedure to generate first weighted bipartite graph is presented in the following algorithm.

Algorithm 1. Generating first weighted bipartite graph

Step 1: Node construction. Initially, there is no node in graph $\boldsymbol{G}_{1}^{\boldsymbol{\tau}}$.Let $\boldsymbol{t}$ be time at which the first request from a customer arrived. Set period $\boldsymbol{\tau}=\boldsymbol{\tau}_{\mathbf{1}}$, where the first period $\boldsymbol{\tau}_{\mathbf{1}}=[\boldsymbol{t}, \boldsymbol{t}+$ $\left.\boldsymbol{\delta}-\boldsymbol{O p} \boldsymbol{p} \boldsymbol{t}_{-} \boldsymbol{T}\right), \boldsymbol{\delta}$ be an acceptable time limit for a customer waiting for a decision to be picked up; and $\boldsymbol{O} \boldsymbol{p} \boldsymbol{t}_{\boldsymbol{T}}$ be time to do assignment optimization. For the next period, set $\boldsymbol{\tau}_{\boldsymbol{i}}=\left[\boldsymbol{t}+(\boldsymbol{i}-\mathbf{1}) \boldsymbol{\delta}-\boldsymbol{O p} \boldsymbol{t}_{T}, \boldsymbol{t}+\boldsymbol{i} * \boldsymbol{\delta}-\boldsymbol{o p} \boldsymbol{t}_{T}\right)$, for $\boldsymbol{i}=2,3, \ldots$. In this study we set $\boldsymbol{\delta}=60$ " and $\boldsymbol{O} \boldsymbol{p} \boldsymbol{t}_{\boldsymbol{T}}=\mathbf{1 0}$ ". Create a set $\boldsymbol{P}^{\tau}$ consisting of all request customers with request time $\boldsymbol{t}_{\text {request_ } P_{k l}^{\boldsymbol{\tau}}}$ in period $\boldsymbol{\tau}_{\boldsymbol{i}}$ and all assigned customers in the previous period $\boldsymbol{\tau}_{\boldsymbol{i}-\mathbf{1}}$ who still not get a customer pair to share a ride in ride splitting service.

Create a set $\boldsymbol{V}^{\boldsymbol{\tau}}$ consisting of all available vehicle in period $\boldsymbol{\tau}_{\boldsymbol{i}}$ including all vehicle which still only assigned to one request customer in the previous period $\boldsymbol{\tau}_{\boldsymbol{i}-\mathbf{1}}$.

Then set $\boldsymbol{N}_{\mathbf{1}}^{\boldsymbol{\tau}}=\boldsymbol{V}^{\boldsymbol{\tau}} \cup \boldsymbol{P}^{\boldsymbol{\tau}}$, be the set of nodes of graph $\boldsymbol{G}_{\mathbf{1}}^{\boldsymbol{\tau}}$.

Step 2: Shortest path, distance and travel time determination. For each customer in $\boldsymbol{P}^{\boldsymbol{\tau}}$ and each vehicle in $\boldsymbol{V}^{\boldsymbol{\tau}}$, determine shortest path passenger's origin-destination to get $\boldsymbol{r o u t e}_{\boldsymbol{o d}} \boldsymbol{P}_{\boldsymbol{k l}}^{\boldsymbol{\tau}}$ and

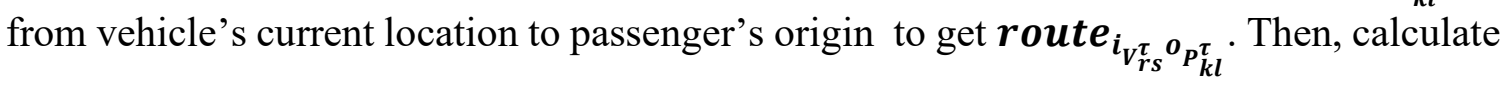

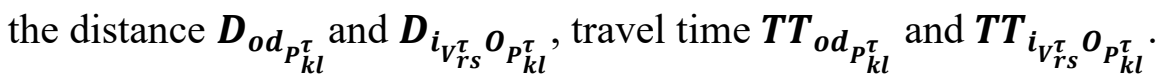

Step 3: Departure time windows, arrival time windows, and max ride time calculation. For each customer in $\boldsymbol{P}^{\boldsymbol{\tau}}$, calculate earliest and latest departure time, earliest and latest arrival time and maximum ride time using equation (1)-(5). In this study we set $\boldsymbol{\varepsilon}, \boldsymbol{\mu}=\mathbf{0 . 2}$, $\lambda_{\text {early }}=5^{\prime}, \lambda_{\text {late }}=15^{\prime}$ and $t_{\text {service }_{-P_{k l}^{\tau}}^{\tau}}^{V_{r s}}=1^{\prime}$.

Step 4: Feasible match determination and edge construction. For each vehicle in $\boldsymbol{V}^{\boldsymbol{\tau}}$ and for each customer in $\boldsymbol{P}^{\boldsymbol{\tau}}$, determine whether a vehicle is feasible to serve a customer by using feasible criterion (6)-(8). Then node $\boldsymbol{V}_{\boldsymbol{r} \boldsymbol{s}}^{\boldsymbol{\tau}}$ in $\boldsymbol{V}^{\boldsymbol{\tau}}$ is adjacent to node $\boldsymbol{P}_{\boldsymbol{k} \boldsymbol{l}}^{\boldsymbol{\tau}}$ in $\boldsymbol{P}^{\boldsymbol{\tau}}$, or $\left(\boldsymbol{V}_{\boldsymbol{r} \boldsymbol{s}}^{\boldsymbol{\tau}}, \boldsymbol{P}_{\boldsymbol{k} \boldsymbol{l}}^{\boldsymbol{\tau}}\right)$ is an edge in $\boldsymbol{E}_{\mathbf{1}}^{\boldsymbol{\tau}}$ if and only if vehicle $\boldsymbol{V}_{\boldsymbol{r}}^{\boldsymbol{\tau}}$ is met the feasible criterion in (6) - (8) to serve customer $\boldsymbol{P}_{k l}^{\tau}$. Then $\boldsymbol{E}_{1}^{\tau}=\left\{\left(\boldsymbol{V}_{r s}^{\tau}, \boldsymbol{P}_{k l}^{\tau}\right) \mid \boldsymbol{P}_{k l}^{\tau}\right.$ and $\boldsymbol{V}_{r s}^{\tau}$ are

feasible match; $\left.V_{r s}^{\tau} \in V^{\tau}, P_{k l}^{\tau} \in P^{\tau}\right\}$.

Step 5: Weight calculation. For each edge in $\boldsymbol{E}_{\mathbf{1}}^{\boldsymbol{\tau}}$ calculate its weight, where the weight is the fare that has to be paid by passenger $\boldsymbol{P}_{\boldsymbol{k} \boldsymbol{l}}^{\boldsymbol{\tau}}$ if served by vehicle $\boldsymbol{V}_{\boldsymbol{r} \boldsymbol{s}}^{\boldsymbol{\tau}}$, using equation (9).

Step 6: Output. From step 1 to step 5, set graph $\boldsymbol{G}_{\mathbf{1}}^{\boldsymbol{\tau}}=\left(\boldsymbol{N}_{\mathbf{1}}^{\boldsymbol{\tau}}, \boldsymbol{E}_{\mathbf{1}}^{\boldsymbol{\tau}}\right)$.

The next stage is to perfomed Algorithm 2 with the following procedure.

Algorithm 2. Generating The Second Weighted Bipartite Graph

Step 1: Node construction. Initially, there is no node in graph $\boldsymbol{G}_{2}^{\boldsymbol{\tau}}$.

Let $\boldsymbol{N}_{\mathbf{1}}^{\boldsymbol{\tau}}$ and $\boldsymbol{E}_{\mathbf{1}}^{\boldsymbol{\tau}}$ be the set of nodes and the set of edges of $\boldsymbol{G}_{\mathbf{1}}^{\boldsymbol{\tau}}$ from algorithm 1

For $\boldsymbol{V}_{r s}^{\boldsymbol{\tau}} \in \boldsymbol{V}^{\boldsymbol{\tau}}$ and $\boldsymbol{P}_{k l}^{\boldsymbol{\tau}} \in \boldsymbol{P}^{\boldsymbol{\tau}}$, create a set $\boldsymbol{V}^{\boldsymbol{\tau}} \boldsymbol{P}^{\boldsymbol{\tau}}$ consisting all pairs of $\boldsymbol{V}_{r s}^{\boldsymbol{\tau}} \boldsymbol{P}_{k \boldsymbol{l}}^{\boldsymbol{\tau}}$, where $\left(\boldsymbol{V}_{r s}^{\boldsymbol{\tau}}, \boldsymbol{P}_{k l}^{\boldsymbol{\tau}}\right)$ is an edge in $\boldsymbol{E}_{\mathbf{1}}^{\tau}$. Create a set $\boldsymbol{D} \boldsymbol{V}^{\boldsymbol{\tau}} \boldsymbol{P}^{\tau}$, a duplication set of $\boldsymbol{V}^{\boldsymbol{\tau}} \boldsymbol{P}^{\tau}$.

That is $D V^{\tau} P^{\tau}=\left\{V_{r^{\prime} s^{\prime}}^{\boldsymbol{\tau}} P_{k^{\prime} \boldsymbol{l}^{\prime}}^{\boldsymbol{\tau}} \mid\right.$ if $\left.\boldsymbol{V}_{r s}^{\boldsymbol{\tau}} \boldsymbol{P}_{k \boldsymbol{l}}^{\boldsymbol{\tau}} \in \boldsymbol{V}^{\boldsymbol{\tau}} \boldsymbol{P}^{\boldsymbol{\tau}}\right\}$.

Then set $\boldsymbol{N}_{\mathbf{2}}^{\boldsymbol{\tau}}=\boldsymbol{V}^{\boldsymbol{\tau}} \boldsymbol{P}^{\boldsymbol{\tau}} \cup \boldsymbol{D} \boldsymbol{V}^{\boldsymbol{\tau}} \boldsymbol{P}^{\boldsymbol{\tau}}$ be a bipartite set of nodes of graph $\boldsymbol{G}_{\mathbf{2}}^{\boldsymbol{\tau}}$. 
Step 2: Vehicle route, distance and travel time determination. For each pair of nodes $\boldsymbol{V}_{\boldsymbol{r} \boldsymbol{s}}^{\boldsymbol{\tau}} \boldsymbol{P}_{\boldsymbol{k} \boldsymbol{l}}^{\boldsymbol{\tau}}$ in $\boldsymbol{V}^{\boldsymbol{\tau}} \boldsymbol{P}^{\boldsymbol{\tau}}$ and $\boldsymbol{V}_{\boldsymbol{r}^{\prime} \boldsymbol{s}^{\prime}}^{\boldsymbol{\tau}} \boldsymbol{P}_{\boldsymbol{k}^{\prime} \boldsymbol{l}^{\prime}}^{\boldsymbol{\tau}}$ in $\boldsymbol{D} \boldsymbol{V}^{\boldsymbol{\tau}} \boldsymbol{P}^{\boldsymbol{\tau}}$, with $\boldsymbol{r}=\boldsymbol{r}^{\prime}$ and $\boldsymbol{s}=\boldsymbol{s}^{\prime}$, determine shortest path from vehicle's current location to the first passenger's origin, then to the second passenger's

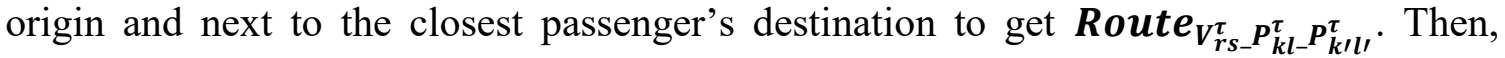

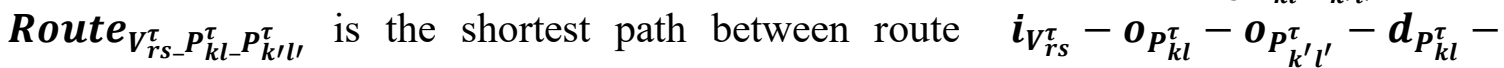
$\boldsymbol{d}_{\boldsymbol{P}_{\boldsymbol{k}^{\prime} l^{\prime}{ }^{\tau}}}$ and route $\boldsymbol{i}_{\boldsymbol{V}_{r s}^{\tau}}-\boldsymbol{o}_{\boldsymbol{P}_{\boldsymbol{k} l}^{\tau}}^{\boldsymbol{\tau}}-\boldsymbol{o}_{\boldsymbol{P}_{\boldsymbol{k}^{\prime} \boldsymbol{l}^{\prime}}^{\tau}}-\boldsymbol{d}_{\boldsymbol{P}_{\boldsymbol{k}^{\prime} \boldsymbol{l}^{\prime}}^{\tau}}-\boldsymbol{d}_{\boldsymbol{P}_{\boldsymbol{k} \boldsymbol{l}}^{\tau}}$. Next, calculate the distance:

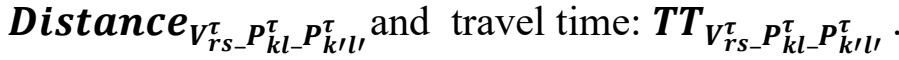

Step 3: Feasible match determination and edge construction. For nodes $V_{r S}^{\tau} P_{k l}^{\tau}$ in $V^{\tau} P^{\tau}$ and $V_{r^{\prime} s^{\prime}}^{\tau} P_{k^{\prime} l^{\prime}}^{\tau}$ in $D V^{\tau} P^{\tau}$, with $r=r^{\prime}$ and $s=s^{\prime}$, check if the vehicle $V_{r s}^{\tau}$ is feasible to serve customers $P_{k l}^{\tau}$ and $P_{k \prime l}^{\tau}$, by using feasible criterion in (10)-(24), then node $V_{r s}^{\tau} P_{k l}^{\tau}$ is adjacent to node $\boldsymbol{V}_{\boldsymbol{r}^{\prime} \boldsymbol{S}^{\prime}}^{\boldsymbol{\tau}} \boldsymbol{P}_{\boldsymbol{k}^{\prime} \boldsymbol{l}^{\prime}}^{\boldsymbol{\tau}}$, or $\left(\boldsymbol{V}_{\boldsymbol{r} \boldsymbol{s}}^{\boldsymbol{\tau}} \boldsymbol{P}_{\boldsymbol{k} \boldsymbol{l}}^{\boldsymbol{\tau}}, \boldsymbol{V}_{\boldsymbol{r}^{\prime} \boldsymbol{s}^{\prime}}^{\boldsymbol{\tau}} \boldsymbol{P}_{\boldsymbol{k}^{\prime} \boldsymbol{l}^{\prime}}^{\boldsymbol{\tau}}\right)$ is an edge in $\boldsymbol{E}_{\mathbf{2}}^{\boldsymbol{\tau}}$.

Step 4: Weight calculation. For each edge in $\boldsymbol{E}_{2}^{\boldsymbol{\tau}}$, calculate vehicle's operational cost and profit gained, passenger's total waiting time and its money value, and the edge weight using formula (25)-(29).

Step 5: Output. From step 1-step 4, set graph $\boldsymbol{G}_{2}^{\boldsymbol{\tau}}=\left(\boldsymbol{N}_{2}^{\boldsymbol{\tau}}, \boldsymbol{E}_{2}^{\boldsymbol{\tau}}\right)$.

Finally, performed The Greedy Heuristic Algorithm based on [20] to solve the mathematical model (30)-(33) for the optimization problem.

Algorithm 3. The Greedy Heuristic Algorithm

Step 1: Select the edge in graph $\boldsymbol{G}_{2}^{\boldsymbol{\tau}}$ with the largest weight and add it to the matching. Let the edge with the largest weight in $\boldsymbol{E}_{2}^{\boldsymbol{\tau}}$ is $\left(\boldsymbol{V}_{r s}^{\boldsymbol{\tau}} \boldsymbol{P}_{\boldsymbol{k} l}^{\boldsymbol{\tau}}, \boldsymbol{V}_{\boldsymbol{r}^{\prime} \boldsymbol{s}^{\prime}}^{\boldsymbol{\tau}} \boldsymbol{P}_{\boldsymbol{k} / \boldsymbol{l}^{\prime}}^{\boldsymbol{\tau}}\right)$, then set the vehicle $\boldsymbol{V}_{\boldsymbol{r} s}^{\boldsymbol{\tau}}$ serves customers $\boldsymbol{P}_{\boldsymbol{k} \boldsymbol{l}}^{\boldsymbol{\tau}}$ and $\boldsymbol{P}_{\boldsymbol{k} \boldsymbol{l} \boldsymbol{l}}^{\boldsymbol{\tau}}$. Update the vehicle $\boldsymbol{V}_{\boldsymbol{r} \boldsymbol{s}}^{\boldsymbol{\tau}}$ ' s occupation: $\boldsymbol{V}_{\boldsymbol{r} \boldsymbol{s}_{-}}^{\boldsymbol{\tau}} \boldsymbol{o c \boldsymbol { c }}$ and capacity: $\boldsymbol{Q}_{V_{r s}^{\tau}}$.

Step 2: Delete the endpoints of the edge selected in step 1, all nodes related to vehicles $\boldsymbol{V}_{r s}^{\boldsymbol{\tau}}$ and $\boldsymbol{V}_{\boldsymbol{r}^{\prime} \boldsymbol{s}^{\prime},}^{\boldsymbol{\tau}}$, customers $\boldsymbol{P}_{\boldsymbol{k} \boldsymbol{l}}^{\boldsymbol{\tau}}$ and $\boldsymbol{P}_{\boldsymbol{k}^{\prime} \boldsymbol{l},}^{\boldsymbol{\tau}}$, and all edges incident to these nodes. If the graph contains at least two nodes, return to step 1; otherwise stop.

\section{COMPUTATIONAL EXPERIMENTS}

To test the model and its solution methodology, in this paper we use two periods of time, which consists of six request customers and six available vehicles and three values for parameter $\boldsymbol{\alpha}$ (profit sharing multiplier factor) as comparation, those are $85 \%, 90 \%$ and $95 \%$. The consideration to use three $\boldsymbol{\alpha}$ values is based on the willingness of the driver (and the operator) to share profit with the initial operator requested by the customer and to keep being profitable for the serving driver (operator). All experiments in this study is coded with Python 3.7 .

In the meantime, the number of operators (platforms) providing online taxi services used is two platforms, while the tariff for the ride-splitting service charged to each passenger from each platform is using three cases as a comparison. Those cases are the equal tariff, $5 \%$ and $10 \%$ difference in tariff. Table 1 describes the fare charged by platform 1 and 2 for all cases. In the first case, the fare charged by platform 1 and 2 is $2 \$$ / distance unit. At the second case, the difference in tariff between platform 1 and 2 is $5 \%$, whereas the fare charged by platform 1 to the customer in ride-splitting service is $2 \$$ /distance unit, while in platform 2 ,

it is $2.1 \$$ /distance unit. While in the last case, the difference in tariff between platform 1 and 2 is $10 \%$, whereas the fare charged by platform 1 to the customer in ride-splitting service is $2 \$$ /distance unit while in platform 2 , it is $2.2 \$$ /distance unit. With the three fare difference cases, it will be seen that the resource sharing scheme used with a certain limit value of profit share, can still be profitable for the driver (and operator) even though there is a difference for the 
cheaper fare paid by the customer. Next, the optimization of the ride-splitting service with the resource sharing scheme compared to the optimization without using the scheme, by taking the value of $w_{V_{r s}^{\tau}}^{P^{\tau}}=1$

Table 1. Fare charged by Platform 1 and 2

\begin{tabular}{|c|c|c|}
\hline Case & $\begin{array}{c}\text { Fare of Platform } 1 \\
\text { per distance unit }\end{array}$ & $\begin{array}{c}\text { Fare of Platform } 2 \\
\text { per distance unit }\end{array}$ \\
\hline For Equal tariff & $2 \$$ & $2 \$$ \\
\hline For $5 \%$ difference & $2 \$$ & $2.1 \$$ \\
\hline For $10 \%$ difference & $2 \$$ & $2.2 \$$ \\
\hline
\end{tabular}

Gradually, there come four request customers in the first period and two request customers in the second period, where there are four available vehicles in the first period and two new available vehicles in the second period.

Let figure 1 ilustrates example of a road transportation network where the passenger's origin and vehicle location are located in the first period. Assume that one distance unit can be traveled in one time unit. The weight of each link describes the distance between two different nodes, for example the distance between node 1 and 4 is 16 distance unit.

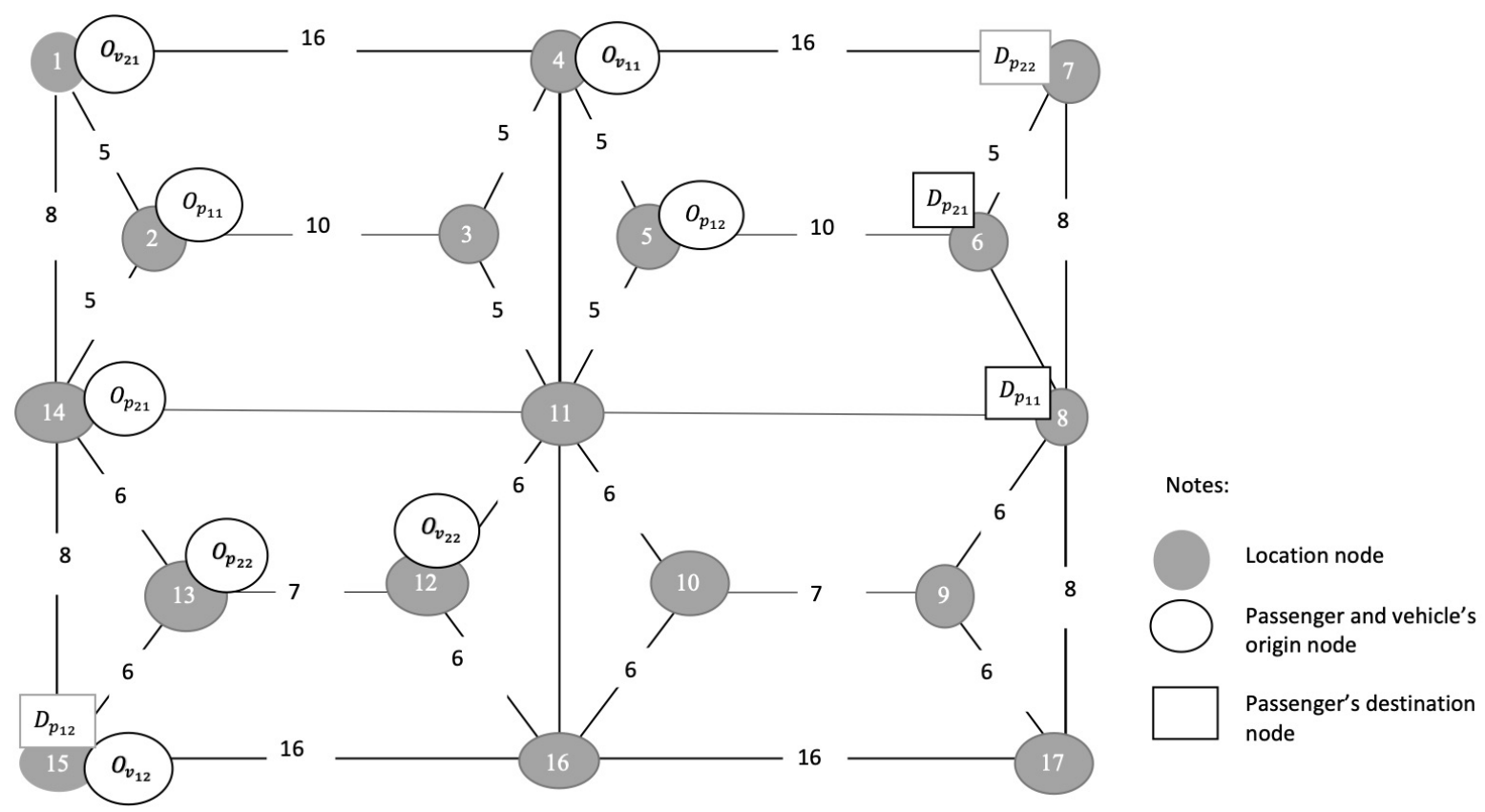

Fig.1 Ilustration of Road Transportation Network in The First Period

Let the first period start at $7^{00}$ and end at $7^{01}$, and the list of customer requests given in the table 2. From table 2, in the first period, there are four customers: $P_{11}, P_{21}, P_{12}$ and $P_{22}$ which request ride splitting services. Let $P_{11}$ be the first customer which request a service (vehicle) from platform $1, P_{21}$ be the first customer which request a service from platform 2 . The origin (pick up) location of $P_{11}$ is at node 2, meanwhile the origin of $P_{21}$ is at node 14. The destination (drop off) location of $P_{11}$ is at node 8 and $P_{21}$ is at node 6 . The number of passengers per request of customer $P_{11}$ is 1 passenger, which has to be picked up between $7^{01}-7^{16}$, meanwhile a request of customer $P_{21}$ consists of 2 passengers, which has to be picked up between $7^{01}$ $7^{16}$.

Table 2. List of Customer Requests in The First Period 


\begin{tabular}{|c|c|c|c|c|c|c|}
\hline customer & $t_{\text {request_P }} P_{k l}$ & $o_{P_{k l}}$ & $d_{P_{k l}}$ & $e_{\text {dept_P}} P_{k l}$ & $l_{\text {dept_P}} P_{k l}$ & $q_{P_{k l}}$ \\
\hline$P_{11}$ & $7^{00}$ & 2 & 8 & $7^{01}$ & $7^{16}$ & 1 \\
\hline$P_{12}$ & $7^{00}$ & 5 & 15 & $7^{01}$ & $7^{16}$ & 2 \\
\hline$P_{21}$ & $7^{00}$ & 14 & 6 & $7^{01}$ & $7^{16}$ & 2 \\
\hline$P_{22}$ & $7^{00}$ & 13 & 7 & $7^{01}$ & $7^{16}$ & 1 \\
\hline
\end{tabular}

There are four available vehicles in the first period, which are vehicle $V_{11}$ and $V_{12}$ from platform 1 , and vehicle $V_{21}$ and $V_{22}$ from platform 2. Data of available vehicle's locations and capacities between $7^{00}-7^{01}$ is given by table 3 .

Table 3. Data of Available Vehicles in The First Period

\begin{tabular}{lrrr}
\hline vehicle & $\boldsymbol{i}_{\boldsymbol{V}_{\boldsymbol{r} \boldsymbol{s}}}$ & $\boldsymbol{t}_{\boldsymbol{i}_{\boldsymbol{V}_{\boldsymbol{r} \boldsymbol{r}}}}^{\boldsymbol{V}_{\boldsymbol{r}}}$ & $\boldsymbol{Q}_{\boldsymbol{V}_{\boldsymbol{r} \boldsymbol{s}}}$ \\
\hline $\boldsymbol{V}_{\mathbf{1 1}}$ & 4 & $7^{00}$ & 4 \\
\hline $\boldsymbol{V}_{\mathbf{2 1}}$ & 1 & $7^{00}$ & 4 \\
\hline $\boldsymbol{V}_{\mathbf{1 2}}$ & 15 & $7^{00}$ & 4 \\
\hline $\boldsymbol{V}_{\mathbf{2 2}}$ & 12 & $7^{00}$ & 4 \\
\hline
\end{tabular}

Let $c_{V_{r S}^{\tau}}$, the vehicle cost per distance unit, is $1 \$$ and $\overline{\overline{w t}}_{\text {money }}$, the money value of passenger's waiting time, is $1 \$$ per minute. Using the solution method in section 4 with three fare difference cases, the optimum assignment result in the first period is described on table 4 and the profit gained by driver is described in figure 2 .

Table 4. The Optimum Assignment Result in Period 1

\begin{tabular}{|c|c|c|}
\hline & $\begin{array}{c}\text { Ride Splitting with } \\
\text { resource sharing scheme, } \\
\text { for } \boldsymbol{\alpha}=\mathbf{8 5} \%, 90 \% \text { and } 95 \%\end{array}$ & $\begin{array}{l}\text { Ride Splitting without } \\
\text { resource sharing scheme }\end{array}$ \\
\hline $\begin{array}{l}\text { Assignment Result } \\
\text { in Period } 1\end{array}$ & $\begin{array}{l}V_{21} \text { is serving } P_{11} \text { and } P_{21} \\
V_{22} \text { is serving } P_{22} \\
V_{11} \text { is serving } P_{12} \\
V_{12} \text { is not yet serving } \\
\text { any customer }\end{array}$ & $\begin{array}{l}V_{22} \text { is serving } P_{21} \text { and } P_{22} \\
V_{12} \text { is serving } P_{11} \\
V_{11} \text { is serving } P_{12} \text {. } \\
V_{21} \text { is not yet serving } \\
\text { any customer }\end{array}$ \\
\hline Total vehicle used & 3 & 3 \\
\hline $\begin{array}{l}\text { Total passenger's } \\
\text { waiting time }\end{array}$ & 17 minutes & 31 minutes \\
\hline
\end{tabular}

It can be seen from table 4, total passenger's waiting time to be picked up by a vehicle for the ride splitting service with sharing platform scheme in the first period is 17 minutes, while in the ride splitting service without sharing platform scheme is 31 time unit. 


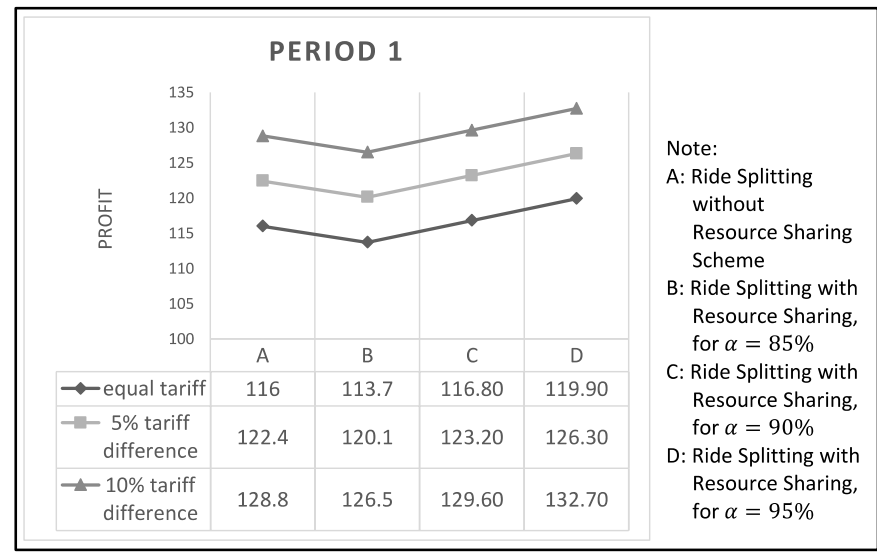

Fig.2 Profit gained comparison in the first period

Based on figure 2, the profit gained by ride splitting service without sharing platform scheme (A) for equal tariff case is $116 \$$, while ride splitting service with sharing platform scheme for $\alpha=85 \%$ (B), $\alpha=90 \%$ (C) and $\alpha=95 \%$ (D) are $113,7 \$, 116,8 \$$ and $119,9 \$$ respectively. It can be seen that profit gained by ride splitting service with sharing platform scheme using $\alpha=90 \%$ (C) and 95\% (D) for all fare difference cases are higher than ride splitting service without sharing platform scheme (A). While, ride splitting service with sharing platform scheme using $\alpha=85 \%$ (B) for all fare difference cases is gaining profit lower than ride splitting service without sharing platform scheme (A). Based on the simulation, the parameter value for profit sharing platform scheme will result in higher profit than without sharing platform scheme when the value is greater than or equal to 0.9 ( $\alpha=90 \%)$. table 5 .

In the second period, there are two new customer requests, summarized in the following

Table 5. List of Customer Requests in Second Period

\begin{tabular}{|c|c|c|c|c|c|c|}
\hline customer & $t_{\text {request_P}}{ }_{k l}$ & $\boldsymbol{o}_{P_{k l}}$ & $d_{P_{k l}}$ & $\boldsymbol{e}_{\text {dept_P}} P_{k l}$ & $\boldsymbol{l}_{\text {dept_} P_{k l}}$ & $q_{P_{k l}}$ \\
\hline$P_{13}$ & $7^{01}$ & 16 & 7 & $7^{02}$ & $7^{17}$ & 1 \\
\hline$P_{23}$ & $7^{01}$ & 11 & 15 & $7^{02}$ & $7^{17}$ & 2 \\
\hline
\end{tabular}

Meanwhile, available vehicles in the second period is summarized in table 6 , where there are three vehicles originating from the first period and two new vehicles from the second period. Based on the assignment result in the first period, vehicle $V_{11}$ is serving passenger $P_{12}$, so that available seat left is only 2 , while vehicle $V_{22}$ is serving passenger $P_{22}$, so that vehicle capacity left is only 3 seats.

Table 6. Data of Available Vehicles in The Second Period

\begin{tabular}{|c|c|c|c|}
\hline vehicle & $\boldsymbol{i}_{V_{r s}}$ & $t_{i_{V_{r s}}}^{V_{r s}}$ & $Q_{V_{r s}}$ \\
\hline$V_{11}$ & 4 & $7^{00}$ & 2 \\
\hline$V_{12}$ & 15 & $7^{00}$ & 4 \\
\hline$V_{22}$ & 12 & $7^{00}$ & 3 \\
\hline$V_{13}$ & 3 & $7^{01}$ & 4 \\
\hline$V_{23}$ & 10 & $7^{01}$ & 4 \\
\hline
\end{tabular}

Using the solution method in section 4, the optimum assignment results in the first and second period is described on table 7 and profit gained comparison for three fare difference cases is described in figure 3. 
Table 7.The Optimum Assignment Results in Two Periods

\begin{tabular}{lll}
\hline & $\begin{array}{l}\text { Ride Splitting with } \\
\text { resource sharing scheme, } \\
\text { for } \boldsymbol{\alpha}=\mathbf{8 5} \%, 90 \% \text { or } 95 \%\end{array}$ & $\begin{array}{l}\text { Ride Splitting without } \\
\text { resource sharing scheme }\end{array}$ \\
\hline $\begin{array}{c}\text { Assignment Result in } \\
\text { Period } 1 \text { and } 2\end{array}$ & $V_{21}$ is serving $P_{11}$ and $P_{21}$ & $V_{22}$ is serving $P_{21}$ and $P_{22}$ \\
& $V_{22}$ is serving $P_{22}$ & $V_{12}$ is serving $P_{11}$ \\
& $V_{11}$ is serving $P_{12}$ and $P_{23}$ & $V_{11}$ is serving $P_{12}$. \\
& $V_{23}$ is serving $P_{13}$ & $V_{13}$ is serving $P_{13}$ \\
& $V_{12}$ and $V_{13}$ are not yet & $V_{23}$ is serving $P_{23}$ \\
& serving any customer & $V_{21}$ is not yet serving any \\
& & customer \\
\hline Total vehicle used & 4 (or $66,7 \%$ of vehicle & 5 (or $83,3 \%$ of vehicle \\
& availability) & availability) \\
\hline Total passenger's & 33 minutes & 50 minutes \\
waiting time & & \\
\hline
\end{tabular}

From table 7, it can be seen that total passenger's waiting time for ride splitting service with sharing platform scheme case is only 33 minutes, lower than without sharing platform scheme case, which is 50 minutes, and so is the total vehicle used, the ride splitting service with the scheme only use $66,7 \%$ of available vehicles, while the ride splitting service without the scheme use $83,3 \%$ of available vehicles.

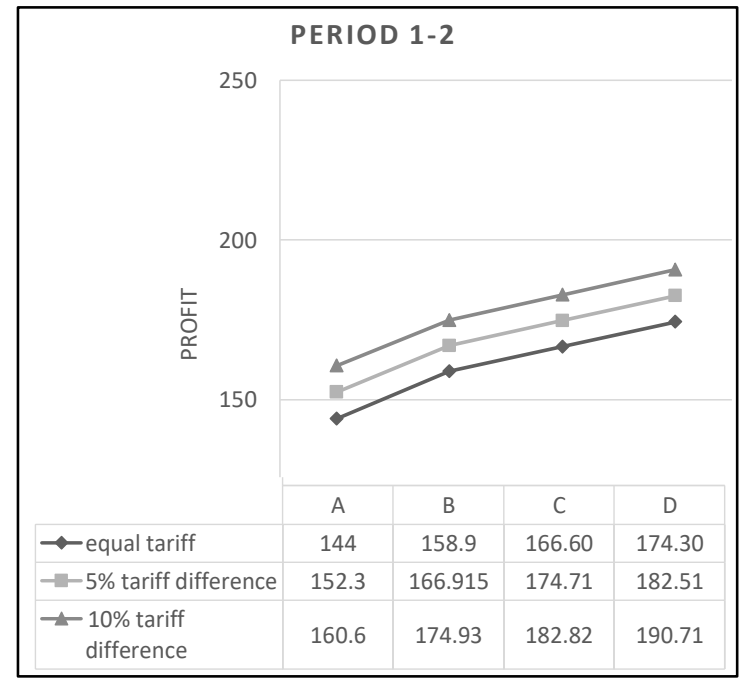

Fig.3 Total Profit Gained Comparison For Total Two Periods

Based on figure 3, total profit gained by ride splitting service without sharing platform scheme (A) for equal tariff case is $144 \$$, while ride splitting service with sharing platform scheme for $\alpha=85 \%$ (B), $\alpha=90 \%$ (C) and $\alpha=95 \%$ (D) are 158,9\$, 166,6\$ and 174,3\$ respectively. It can be seen that profit gained by ride splitting service with sharing platform scheme using $\alpha=85 \%$ (B), 90\%(C) and 95\% (D) for all fare difference cases are higher than ride splitting service without sharing platform scheme (A).

\section{CONCLUSIONS}

Based on the experiment, it can be concluded that the optimization of ride-splitting service with resource-sharing scheme can reduce the vehicle used for online taxi services. Moreover, it can generate higher overall profit for all vehicles serving passenger, and the parameter value 
for profit sharing platform scheme is better greater than or equal to $0,9(\alpha=90 \%)$. Meanwhile, total passenger's waiting time to be picked up by a vehicle for ride splitting service with sharing platform scheme case is lower than without sharing platform scheme case.

This study is still using small instance as an experiment to prove that the optimization of ride-splitting service with resource-sharing scheme is possible to be utilized, so that for the next research, bigger data usage is required

\section{ACKNOWLEDGEMENT}

The authors would like to thank to Kemenristek Dikti and LPDP for scholarship in order the completion of doctoral studies at Universitas Indonesia.

\section{REFERENCES}

[1] Burhan, H., Soehodho, S., and Nahry. (2017). Review on the Development of Ride Sharing System using Online Transportation Service in Jakarta. Proceeding of 6th IEEE International Conference on Advanced Logistics and Transport, pp.173-178.

[2] Anderson, D. N.,(2014). 'Not Just A Taxi'? For-Profit Ridesharing, Driver Strategies, and VMT. Transportation 41, pp.1099-1117. http://dx.doi.org/10.1007/ s11116-014-9531-8.

[3] Rayle, L., Dai, D., Chan, N., Cervero,R., and Shaheen, S. (2015). Just a better taxi? A surveybased comparison of taxis, transit, and ridesourcing services in San Francisco. Transp. Policy, pp.168-178.

[4] Shaheen, S., Cohen, a., and Zohdy, I. (2016). Shared Mobility: Current Practices and Guiding Principles. U.S. Department of Transportation, Federal Highway Administration. Report No. FHWA-HOP-16-022.

[5] Chen, L., Mislove, A., and Wilson, C. (2015). Peeking Beneath the Hood of Uber. In Proc. of the ACM Conference on Internet Measurement Conference, ACM.

[6] Burhan, H., Soehodho, S., and Nahry. (2019). A Resource Sharing (Sharing Platform) Scheme on Online Taxi Services. MATEC Web of Conferences,vol. 270, art.no.03010.

[7] Agatz, N.A.H., Erera, A.L., Savelsbergh, M.W.P., and Wang, X. (2012). Optimization for dynamic ride-sharing: a review. European Journal of Operational Research, vol.223 (2), pp.295-303.

[8] Lu, Q., and Dessouky, M. (2006). A new insertion-based construction heuristic for solving the pickup and delivery problem with hard time windows. European Journal of Operational Research, vol.175 (2), pp.672-687.

[9] Dumas, Y., Desrosiers, J., and Soumis, F. (1991). The pickup and delivery problem with time windows. European Journal of Operations Research, vol.54, pp.7-22.

[10] Toth,P. and Vigo, D. (2002). The Vehicle Routing Problem. Siam, Philadelphia http://dx.doi.org/10.1137/1.9780898718515.

[11] Hosni, H., Naoum-Sawaya, J., and Artail, H. (2014). The shared-taxi problem: Formulation and solution methods. Transp. Res. Part B: Methodol. 70, pp. 303-318.

[12] Wang, X., Dessouky, M., and Ordonez, F. (2015). A pickup and delivery problem for ridesharing considering congestion. Transp. Lett.: Int. J. Transp. Res.,1942787515Y000000002 .

[13] Santos, D.O., and Xavier, E.C. (2015). Taxi and Ride Sharing: A Dynamic Dial-a-Ride Problem with Money as an Incentive. Expert Systems with Applications, vol. 42, pp.6728-6737.

[14] Mahmoudi, M., and Zhou, X. (2017). Finding optimal solutions for vehicle routing problem with pickup and delivery services with time windows: a dynamic programming approach based on state-space-time network representations. Transport. Res. Part B: Methodol. Vol.89, pp.1942.

[15] Bei, X., and Zhang, S. (2018). Algorithms for trip-vehicle assignment in ride-sharing. In: Proceedings of the 32nd AAAI Conference on Artificial Intelligence, pp. 3-9. 
[16] Banerjee, S., Johari, R., and Riquelme, C. (2015). Pricing in ride-share platforms: A queueingtheoretic approach. Working Paper. Available at SSRN: https://ssrn.com/abstract=2568258 or http://dx.doi.org/10.2139/ssrn.2568258.

[17] Chen, Y., and Hu, M. (2017). Pricing and Matching with Forward-Looking Buyers and Sellers. Working Paper. Available at SSRN: https://ssrn.com/abstract $=2859864$ or http://dx.doi.org/10.2139/ssrn.2859864.

[18] Zha, L., Yin, Y., and Xu, Z. (2018). Geometric matching and spatial pricing in ride-sourcing markets. Transportation Research Part C: Emerging Technologies, Vol.92, pp.58-75.

[19] Yang, H., Shao, C., Wang, H., and Ye, J. (2018). Integrated Reward Scheme and Surge Pricing in a Ride Sourcing Market. Report, June 18, 2018. Available at SSRN: https://ssrn.com/abstract=3198081 or http://dx.doi.org/10.2139/ssrn.3198081.

[20] Evans, J.R., and Minieka, E. (1992). Optimization algorithms for networks and graphs, $2^{\text {nd }}$ edition Revised. New York. 